\title{
Müşteri Odaklı Et Tedarik Zincirlerinde Başarı Kriterlerinin Değerlendirilmesi a
}

\author{
Aylin Çalışkan ${ }^{\mathrm{b}, \mathrm{c}}$
}

\section{Özet}

Gıda üreticileri ve perakendecileri rekabet yoğun modern pazarda rekabet avantajı elde edebilmek ve faaliyetlerini sürdürebilmek için müşteri odaklı olmaya daha fazla özen göstermek durumundadırlar. Tüketicilerin tercih ve algılarının farkında olabilmek, benimseyebilmek ve gerekli şekilde yönetebilmek; pazar paylarını iyileştirmek ve gereksiz tedarik zinciri operasyonlarından kaçınabilmek adına faydalıdır. Bu çalışmanın amacı, et tedarik zinciri yönetiminde müşteri odaklı olabilmek adına belirlenen başarılı kriterlerinin hiyerarşik yapısını ortaya koymak ve bu kriterleri etkileme ve etkilenme kuvvetlerine göre sinıflandırmaktır. Bu amaca yönelik literatür araştırmasıyla müşterilerin et satın alma davranışına etki eden kriterler tedarik zinciri yönetimiyle ilgili olacak şekilde derlenmiştir. Daha sonra bu kriterler arasındaki ilişkiler Yorumlayıcı Yapısal Modelleme ve MICMAC analizi ile incelenmiştir. Analizler sonucunda karmaşık ilişkilere sahip olan kriterler arasında hiyerarşik bir model geliştirilmiş ve bağımlı/bağımsız kriterler belirlenmiştir. Elde edilen sonuçlara göre ambalaj ve izlenebilirlik kriterlerinin diğer kriterleri en yüksek etkileme gücüne ve diğer kriterlerden en az etkilenme seviyesine sahip kriterler olduğu tespit edilmiştir.
Anahtar Kelimeler

Tedarik Zinciri

Tüketici Odaklı Lojistik

Tüketici Davranışı

Soğuk Zincir

Makale Hakkında

Geliş Tarihi: 26.04.2020

Kabul Tarihi: 12.10 .2020

Doi: $10.18026 /$ cbayarsos.726964

\section{Success Criteria Evaluation of Customer-Focused Meat Supply Chains}

\begin{abstract}
Food producers and retailers need to pay more attention to being customeroriented in order to gain advantage and continue their activities in the highly competitive market. In order to improve market shares and avoid unnecessary supply chain operations, it is useful to be aware of, adopt and manage consumers' preferences and perceptions. The purpose of this study is to reveal the hierarchical structure of the success criteria of customer-focused meat supply chain management and to classify these criteria according to their impact strengths. To the aim, supply chain management related criteria affecting the meat purchase behavior of customers were compiled through literature review. Then, the relationships between these criteria were examined by Interpretive Structural Modeling and MICMAC analysis. As a result of the analyzes, a hierarchical model and dependent/independent classification are developed among the criteria that had complex relationships. According to the results obtained, it is determined that the packaging and traceability criteria are the criteria that have the highest impact power and the least impacted level from other criteria.
\end{abstract}

Keywords

Supply Chain

Consumer Focused Logistics

Consumer Behavior

Cold Chain

About Article

Received: 26.04 .2020

Accepted: 12.10 .2020

Doi: $10.18026 /$ cbayarsos.726964

\footnotetext{
a İlgili çalışmanın, 3.Ulaştırma ve Lojistik Ulusal Kongresi'nde özet bildiri olarak sunumu gerçekleştirilmiştir.

b İletişim Yazarı: aylin.caliskan@yasar.edu.tr

c Dr. Öğr. Gör., Yaşar Üniversitesi/ Bornova-İzmir, ORCID numarası: 0000-0002-2658-2761
} 


\section{Giriş}

Modern sanayinin temel amacı tüketicileri memnun etmektir. Tedarik zincirinin tüm üyeleri, tesis ve kaynakları, ürün ve hizmetlerini satın alan son tüketiciler olmasaydı var olamazlardı. Dolayısıyla tedarik zincirindeki tüm faaliyetler tüketicilerin ihtiyaçlarını karşılamaya yönelik olmalı ve tüketicinin ne istediğine odaklanmalıdır. Üretim zincirinin son halkası oldukları için tüketicilerin davranışsal kalıplarını incelemek tedarik zinciri yapılanmalarında ve operasyon içeriğinin dizayn edilmesinde önemli rol oynamaktadır (Font-i-Furnols ve Guerrero, 2014). Bu yönde tedarik zinciri yapılanmalarında ve yönetiminde tüketici odaklı yaklaşım benimsenmeye başlanmıştır. İşletmeler müşteri taleplerini karşılamaya çalışırken, bir yandan da hem zaman hem kaynak açısından daha verimli operasyonlar tasarlamaya çalışmaktadır. Hem müşteri odaklı olmak, hem de tedarik zincirini en az maliyette ve en etkili şekilde yönetmek işletmelerin günümüzde zorluk yaşadığı alanlardan biridir. Çünkü müşterilerin özelleştirilmiş, kişiselleştirilmiş ve çok çeşitli ürün ve hizmet talepleri tedarik zincirleri yapılanmalarında esneklik, cevap verebilirlik ve etkili kaynak kullanımı açısından değişikliklere, dolayısıyla maliyet artışına yol açmaktadır (Griffiths vd., 2000)

Gıda tedarik zinciri, gıdanın tarladan çatala kadar olan transfer aşamasında gerçekleşen tüm operasyonları (örneğin; üretim, işleme, dağıtım, pazarlama, perakende yönetimi, tüketim ve bertaraf) kapsamaktadır. Gıda tedarik zincirlerinde hem etkin yönetim gerçekleştirmek hem de müşteri odaklı olmak, gıda ürünlerinin bozulabilir niteliğinden ötürü daha zor ve karmaşıktır (Aung ve Chang, 2014). Özellikle et ve et ürünleri açısından bakıldığında; şarbon, deli dana, köpek eti ve at eti gibi skandallardan sonra piyasada ki et üreticileri ve perakendecilerinin üzerinde etin sağlı̆̆ı, kalitesi ve güvenliğini hem kendi hem tedarikçileriyle birlikte sağlama ve bunu tüketiciye ispat etme üzerine baskılar artmıştır (Yamoah ve Yawson, 2014). Bunun haricinde, et ve et ürünleri müşteriye ulaşırken iyi bir lezzete, kaliteye ve görünüşe, uygun raf ömrüne, yüksek besin değerine ve uygun maliyete sahip olmalıdır (Van Wezemael vd., 2014). Tedarik zinciri operasyonlarında kesim öncesi süreçte hayvanların stres seviyeleri, hijyenik koşulları gibi faktörler dikkate alınırken kesim sonrası süreçte ise kısıtlı tüketim süresine sahip etlerin dokusunun, kokusunun, tadının bozulmadan, kötü bakteri sayısının artmadan, hijyenik koşullarda en kısa sürede tüketicilerin tüketimine sunulmak üzere vitrinlerde yerini alması gerekmektedir. Tedarik zinciri aktörlerinden birinin hassas operasyon gerektiren bir yük türü olan eti layıkıyla işleyememesi, depolayamaması, elleçleyememesi ve/veya taşıyamaması sebebiyle de etin kalitesi büyük ölçüde etkilenmektedir.

Literatürde et tedarik zinciriyle ilgili çalışmaların kısıtlı olduğu görülmektedir. Mevcut çalışmalar genelde et tedarik zinciri süreçlerini incelemekte, zincir dizayn etme amacını gütmekte ve tedarik zinciri sürecinde izlenebilirlik konularını ele almaktadır. Örneğin Miranda-De La Lama ve diğerleri (2009) kesim öncesi lojistik operasyonlarının kuzu etinin kalitesine olan etkisini ele almışlardır. Hobbs (2016) ve Pizzuti ve diğerleri (2017) et tedarik zincirinde izlenebilirliğin desteklenmesi adına öneriler geliştirmişlerdir. Birdir ve Hiçyakmazer (2019) otel işletmelerinde et satın alma ve tedarik sürecini incelemiş, Mohebalizadehgashti ve diğerleri (2020) yeşil et tedarik zinciri ağı dizayn etmişlerdir. Et tedarik zinciri konusundaki kısıtlı arza katkıda bulunan bu çalışmanın en önemli farklılığı çalışmanın tüketici gözünden yapılmasıdır. Araştırma verileri et tedarik zinciri paydaşlarının en son halkası olan et tüketicilerinden toplanmıştır. Dolayısıyla bu araştırmada ağ dizaynı, ulaşım planlaması, mesafe ve yakıt optimizasyonu gibi tedarik zinciri yönetiminin önemli 
kriterlerinden ziyade müşterilerin et satın alma sürecinde dikkate aldıkları seçim kriterlerine odaklanılmıştır. Bu kriterler etin kalitesi (Banović ve diğerleri, 2009), lezzeti (Font-i Furnols ve Guerrero, 2014), rengi (Gracia ve Magistris, 2013), ambalajı, (Geesink ve diğerleri, 2015), fiyatı (Marian ve diğerleri, 2014) ve izlenebilirliğidir (Lee ve diğerleri, 2011). Et ve gıda sektörü tüm bu kriterlerin tüketicilerin satın alma davranışlarını etkilediğinin elbette farkındadır, ancak, bu kriterlerin aralarındaki ilişkileri ve bu ilişkiler doğrultusunda belirtilen faktörleri tedarik zincirleri operasyonlarına nasıl entegre edecekleri konusu belirsizdir.

$\mathrm{Bu}$ araştırmada yorumlayıcı yapısal modelleme yöntemi kullanılarak tüketicilerin et satın alma davranışını etkileyen ve tedarik zinciri operasyonlarından etkilenen kriterler arasındaki ilişkileri temsil etmek için hiyerarşik bir yapı oluşturulmuştur. Daha sonra MICMAC analiz yöntemiyle bu kriterler; etkileyen, bağlantılı, otonom ve bağımlı değişkenler olarak dört farklı kategoriye ayrılmıştır. Bu bulgulara dayanarak tüketici merkezli et tedarik zinciri yönetimi için önerilerde bulunulmuştur.

Mevcut çalışmanın ikinci bölümünde metodolojinin süreç adımları detaylı olarak açıklanmış ve elde edilen verilerle analizler yapılmıştır. Üçüncü bölümde bulgular ortaya konmuştur. Son bölümde ise sonuçlar özetlenerek tartışılmış ve gelecek çalışmalar için önerilerde bulunulmuştur.

\section{Yöntem}

Çeşitli seviyelerde birbirine bağlanmış tüketici odaklı et tedarik zinciri kriterleriyle bir çerçeve çizmek, aralarında ki hiyerarşik ilişkileri ortaya çıarmak, birbirlerini etkileme ve birbirlerinden etkilenme kuvvetlerini belirlemek adına bu çalışmada Yorumlayıcı Yapısal Modelleme (Interpretive Structural Modeling - ISM) ve MICMAC ((Matrice d'Impacts Croisés Multiplication Appliquee a un Classement/ Cross Impact Matrix Multiplication Applied to Classification) yöntemleri kullanılmıştır. ISM yönteminin kullanılma nedeni kriterlerin birbirlerini hangi yönde etkilediğini ortaya koyarak odaklanılması gereken kök kriter veya kriterleri belirlemektir. ISM tekniği, bir problem veya olguyu tanımlayan belirli unsurlar arasındaki ilişkileri tanımlamak için oluşturulmuş bir metodolojidir (Jharkharia ve Shankar, 2005). Unsurların tek başına diğerlerinden bağımsız şekilde ele alınmaktansa, unsurlar arasında oluşturulan doğrudan ve dolaylı ilişkiler konuya daha bütüncül bir bakış açısı kazandırmaktadır (Attri vd., 2013). ISM; süreç dizaynı, kariyer planlaması, müşteri memnuniyeti, ürün dizaynı, stratejik planlama, mühendislik problemleri, karmaşı teknik problemler, finansal karar verme, insan kaynakları, rekabetçi analiz ve elektronik ticaret gibi birçok alan ve konularda sistemi, süreci ve/veya problemi analiz etmede kullanılmaktadır (Wen-li vd., 2003; Singh vd., 2007; Chidambaranathan vd., 2009). MICMAC yönteminin kullanılma nedeni ise tüketici odaklı et tedarik zinciri başarı kriterlerini, birbirlerini etkileme ve birbirlerinden etkilenme kuvvetlerine göre otonom, bağımlı, bağlantı ve bağımsız olarak sinıflandırmaktır. MICMAC tekniği, ISM tekniğini tamamlayıc niteliği sebebiyle tercih edilmektedir (Ahmad vd., 2019). X'in Y'yi, Y'nin Z'yi doğrudan etkilediği; X'in Z'yi veya Z'nin $X^{\prime} i$ etkilemediği bir ilişki sarmalında doğrudan ilişkiler sebebiyle $X$ ile $Z$ arasında da çapraz bir korelasyon oluşmaktadır. X'te gerçekleşen herhangi bir değişikliK dolaylı yoldan Z'yi de eklemektedir. Bu tür ilişkiler gri alan olan tanımlanmaktadır. MICMAC tekniği gri alanı görmezden gelmekte, bir ilişkiyi ya var ya da yok olarak nitelendirmektedir (Dubey ve Ali, 2014). 


\section{Araştırma Tasarımı}

Araştırmanın metodolojisinin tüm süreç adımları Şekil 1'de gösterilmiş ve akabinde her bir adım detaylı olarak açıklanmıştır.

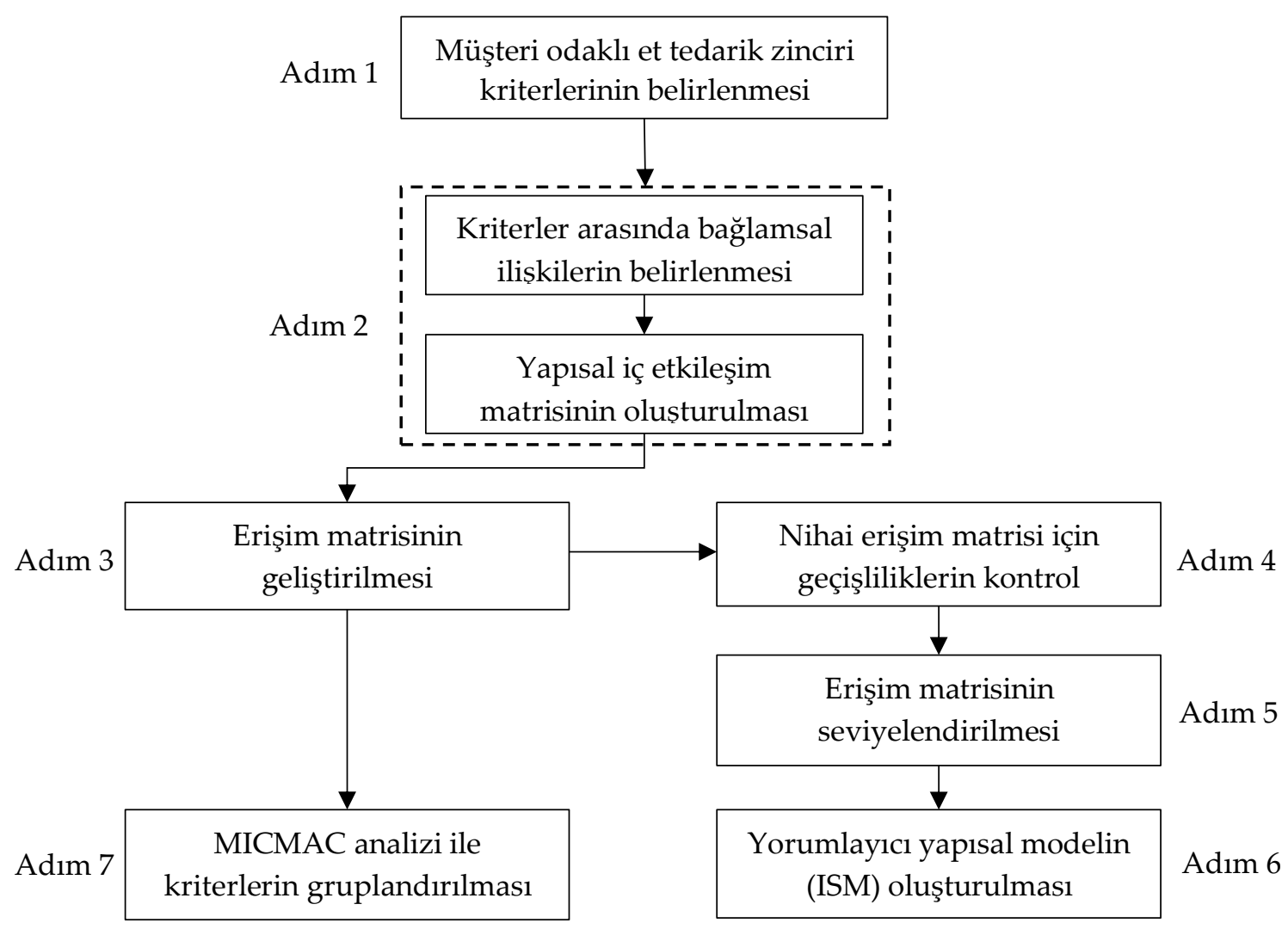

Şekil 1. Çalışmada Kullanılan Metodolojinin Süreç Adımları

\section{Kriterlerin Belirlenmesi}

Araştırmanın birinci adımında literatür araştırması eşliğinde tüketicinin et satın alma davranışını etkileyen kriterler tedarik zinciri yönetimiyle ilgili olacak şekilde derlenmiştir. Et tedarik zinciri kritik başarı faktörleri araştırıldığında; zamanında teslimat, tedarikçilerle uyum, partnerlerle işbirliği, lojistik süreçlerinde senkronizasyon ve kapasite iyileştirmesi gibi kriterler karşımıza çıkmaktadır (Sharma vd.,2017). Müşterilerin et seçim/satın alma davranışını etkileyen kriterlere bakıldığında ise etin menşeisi, hayvanın cinsi, markası, sertifikası, satıcının güvenilirliği ve tutumu, marketin konumu gibi faktörlerin ele alındığ 1 görülmektedir. Bu çalışma, hem tedarik zincirini hem de müşteriyi ilgilendiren kriterlere odaklandığından literatür araştırması da bu yönde gerçekleştirilmiştir. "Et tedarik zinciri", "'et' ve 'tüketici'”, "et satın alma davranış1", "'et' ve 'lojistik'" gibi anahtar kelimelerle veri tabanlarında (Science Direct, Scopus, Web of Science, Google Scholar) araştırma yapılmıştır. Yapılan araştırmalar sonucunda, etin kendi yapısı ve cinsiyle ilgili (örneğin, sı̆̆ır eti, domuz eti, koyun eti, organik et, pirzola, köfte gibi) ve satış yapılan yer ile ilgili (satış personeli, lokasyon gibi)faktörler dikkate alınmayarak tedarik zinciri operasyonlarıyla ilgili tüketicinin et satın alma davranışını etkileyen kriterler derlenmiştir. Bu kriterler etin ambalajını, izlenebilirliğini, lezzetini, rengini, kalitesini ve fiyatını içermektedir. 
Etin paketlenme tarzı ve ambalajı, literatürde de tüketicinin eti satın alma davranışını etkileyen önemli faktörlerden biri olarak karşımıza çıkmaktadır (Geesink vd., 2015). Ambalajlama veya diğer ifadeyle paketleme lojistik fonksiyonlardan biridir dolayısıyla bu çalışmada müşteri odaklı et tedarik zinciri yönetiminin başarı kriterlerinden biri olarak ele alınmıştır. Yapılan araştırmalarda tüketicilerin takip edebildiği, geçmişini ve hangi aşamalardan geçtiğini görebildiği etlere daha fazla ücret ödemeye razı oldukları görülmüştür (Lee vd., 2011). O nedenle tedarik zinciri yönetiminin de önemli bir unsuru olarak izlenebilirlik faktörü de kriterler arasına alınmıştır. Etin tadının kesim sonrası gerçekleştirilen tedarik zinciri faaliyetleri sırasında etkilendiği görüldüğünden, (örneğin depolama ve taşıma durumlarında etin lezzetinin değişmesi (Font-i-Furnols ve Guerrero, 2014), bu unsurda müşterilerin et seçim kriterleri arasına alınmıştır. Etin rengi, satış noktasında müşterinin etin tazeliğini değerlendirmede dikkate aldığ 1 en önemli faktörlerden biri olarak ele alınmaktadır. Müşteriye göre yetersiz kırmızılıkta kahverengiye yakın bir renk, etin sağlıksız ve/veya bozulmuş olduğunun göstergesiyken, kırmızı-mor bir renk ise tazeliğinin göstergesidir (Gracia ve Magistris, 2013). O nedenle tüketicinin eti satın almadan önce ki aşamada etin rengini değerlendirmek müşterilerin karar verme sürecinde oldukça sık kullandıkları bir yöntemdir (Fonti-Furnols ve Luis Guerrero 2014). Etin kalitesinin değerlendirilme süreçleri tüketiciden tüketiciye değişmekle beraber bu süreçte kullanılan kriter ve ölçütleri farklılık göstermektedir. Örneğin, kimine göre etin kalitesinden anlaşılan tazeliği, az kıkırdağa sahip olması, sulu olması, hastalıklı olmaması ve iyi kokulu olmasıdır (Banović vd., 2009). Tüm bu kalite unsurları genelde et pişirildikten sonra fark edilen özelliklerdir. Pişirme işlemi gerçekleşmeden satın alma aşamasında ise etin kaliteli olup olmadığ 1 değerlendirmesi genelde tüketiciler tarafından markaya ve etikete bakarak yapılmaktadır (Grunert vd., 2004). Troy ve Kerry (2010)'ye göre ise tüketiciler etin kalitesini satın alma aşamasında etin rengine göre değerlendirmektedir. Font-i-Furnols ve Guerrero (2014) ise etin rengine ek olarak etin yağ oranını, mermer görünümünü ve etten sızan sıvıyı tüketiciler tarafından et kalitesi değerlendirme faktörleri olarak belirlemiştir. Et kalitesinin değerlendirme aşamasında kullanılan ve farklı çalışmalar tarafından betimlenen tüm bu faktörlerin ortak özelliği etin diş görünüşüyle alakalıdır ve soğuk zincir tedarik zinciri operasyonlarıyla birebir bağlantılıdır. Dolayısıyla kalite unsuru kriterler arasına eklenmiştir. Her ürünün değerlendirilmesinde olduğu gibi et ürününde de fiyat tüketicilerin satın alma karar aşamasında etki eden önemli bir faktör (Marian vd., 2014) olduğundan ve tedarik zinciri faaliyetlerine göre artış gösterdiğinden bu çalışmada da kriter olarak ele alınmıştır.

\section{Katılımcilar}

ISM ve MICMAC tekniklerinde örneklem büyüklüğünün ne olması gerektiğine dair literatürde ortak bir görüş yoktur. ISM yöntemini kullanan çalışmalar incelendiğinde örneklem büyüklüğünün 3 ile 16 arasında değiştiği belirlenmiştir (Jayant vd., 2015). Bu çalışmada belirlenen kriterler arasındaki ikili ilişkileri değerlendirmek adına bir yerel süpermarketin et reyonundan alışveriş yapan 14 tüketiciden veriler toplanmıştır. Araştırmaya katılmayı kabul eden tüketicilerin 8'i kadın, 6'sı erkek; 9'u lisans, 4'ü lise, 1'i yüksek lisans mezunudur. Katılımcıların hepsinin hane olarak aylık gelir miktarı 3500 Türk Lirası'nın üzerindedir. Görüşülen tüketicilerin 9'u haftada ortalama 2 kilogram, 5'i ise ortalama 1 kilogram kırmızı et satın aldıklarını belirtmiştir. 


\section{Verilerin Toplanması ve Analizi}

Tüketicilerden toplanan veriler ile çoğunluk prensibini gözeterek yapısal iç-etkileşim matrisi oluşturulmuştur (Tablo 1). Bu matriste kullanılan sembollerin açıklaması şu şekildedir;

a. $\mathrm{V}-i$ kriterinin $j$ kriterinin oluşumuna katkısı vardır.

b. A- $j$ kriterinin $i$ kriterinin oluşumuna katkısı vardır.

c. $\mathrm{X}-i$ ve $j$ kriterleri birbirlerine etki eder.

d. O- $i$ ve $j$ kriterleri arasında bir ilişki yoktur.

Tablo 1. Yapısal İç-Etkileşim Matrisi

\begin{tabular}{lcccccc}
\hline & & 6 & 5 & 4 & 3 & 2 \\
\hline $\mathbf{1}$ & Kalite & A & V & A & A & A \\
$\mathbf{3}$ & Lezzet & O & V & A & X & - \\
4 & Renk & O & V & A & - & - \\
5 & Ambalaj & X & V & - & - & - \\
6 & Fiyat & A & - & - & - & - \\
\hline
\end{tabular}

Araştırmanın üçüncü adımında yapısal iç-etkileşim matrisinde kullanılan notasyonlardan yararlanılarak erişim matrisi oluşturulmuştur (Tablo 2). Bu aşamada amaç, iç-etkileşim matrisinde kullanılan harflerin sayısal ifadelere dönüştürülmesidir. Sayısallaştırma işlemi aşağıdaki gibi gerçekleştirilmektedir;

a. $i$ kriterinin $j$ kriterinin oluşumuna katkısı varsa $1, j$ kriterinin $i$ kriterinin oluşumuna katkısı yoksa 0 yazılır.

b. Tanımlama $i^{\prime}$ den $j^{\prime}$ ye tek yönlü yapıldı̆̆ından tüm tablo doldurulur.

c. Her kriterin kendisine etkisi olduğundan matrisinin köşegen elemanları 1 değerini alır.

Tablo 2. Erişim Matrisi

\begin{tabular}{llllllll}
\hline & $\mathbf{6}$ & $\mathbf{5}$ & $\mathbf{4}$ & $\mathbf{3}$ & $\mathbf{2}$ & $\mathbf{1}$ \\
\hline $\mathbf{1}$ & Kalite & 0 & 1 & 0 & 0 & 0 & 1 \\
$\mathbf{2}$ & Lezzet & 0 & 1 & 0 & 1 & 1 & 1 \\
$\mathbf{3}$ & Renk & 0 & 1 & 0 & 1 & 1 & 1 \\
$\mathbf{4}$ & Ambalaj & 1 & 1 & 1 & 1 & 1 & 1 \\
$\mathbf{5}$ & Fiyat & 0 & 1 & 0 & 0 & 0 & 0 \\
$\mathbf{6}$ & İlenebilirlik & 1 & 1 & 1 & 0 & 0 & 1 \\
\hline
\end{tabular}


Dördüncü adımda ise oluşturulan erişim matrisinde geçişlilik durumları kontrol edilmiş, durağan değerler elde edilene kadar tekrarlanmış ve nihai erişim matrisi (Tablo 3) oluşturulmuştur. Geçişlilik kontrolünde amaç kriterler arasındaki endirekt ilişkileri ortaya çıkarmaktadır. Örneğin renk kriteri lezzet kriterini etkiliyorsa, lezzet kriteri ise fiyat kriterini etkiliyorsa o zaman renk kriterinin fiyat kriterini etkilediği kabul edilmektedir.

Tablo 3. Nihai Erişim Matrisi

\begin{tabular}{llllllll}
\hline & & $\mathbf{6}$ & $\mathbf{5}$ & $\mathbf{4}$ & $\mathbf{3}$ & $\mathbf{2}$ & $\mathbf{1}$ \\
\hline $\mathbf{1}$ & Kalite & 0 & 1 & 0 & 0 & 0 & 1 \\
$\mathbf{2}$ & Lezzet & 0 & 1 & 0 & 1 & 1 & 1 \\
$\mathbf{3}$ & Renk & 0 & 1 & 0 & 1 & 1 & 1 \\
$\mathbf{4}$ & Ambalaj & 1 & 1 & 1 & 1 & 1 & 1 \\
$\mathbf{5}$ & Fiyat & 0 & 1 & 0 & 0 & 0 & 0 \\
$\mathbf{6}$ & İzlenebilirlik & 1 & 1 & 1 & $1^{*}$ & $1^{*}$ & 1 \\
\hline
\end{tabular}

Metodolojinin beşinci adımında erişim matrisinde erişim, öncül ve kesişim kümeleri belirlenerek hiyerarşik seviyelendirme işlemi gerçekleştirilmiştir. Erişim kümesi bir faktörün etkilediği tüm faktörlerden oluşan kümedir. Öncül küme ise bir faktörü etkileyen tüm faktörlerin oluşturduğu kümedir. Bu kümeler belirlendikten sonra iki kümenin kesişiminden oluşan kesişim kümeleri belirlenmiş ve seviyelendirme işlemi yapılmıştır (Tablo 4). İlk aşamada, bir faktörün erişim kümesi ile kesişim kümesi eşit ise bu faktörün hiyerarşik seviyesi I olarak belirlenir. Diğer aşamalarda ise seviyelendirilen faktörler diğer kümelerden çıkartılarak aynı işlem tekrarlanır ve seviyeler belirlenir.

Tablo 4. Seviyelendirme

\begin{tabular}{ccccc}
\hline Kriter & Erişim kümesi & Öncül küme & $\begin{array}{c}\text { Kesişim } \\
\text { kümesi }\end{array}$ & Seviye \\
\hline $\mathbf{1}$ & 1,5 & $1,2,3,4,6$ & 1 & II \\
$\mathbf{2}$ & $1,2,3,5$ & $2,3,4,6$ & 2,3 & III \\
$\mathbf{3}$ & $1,2,3,5$ & $2,3,4,6$ & 2,3 & III \\
$\mathbf{4}$ & $1,2,3,4,5,6$ & 4,6 & 4,6 & IV \\
$\mathbf{5}$ & 5 & $1,2,3,4,5,6$ & 5 & I \\
$\mathbf{6}$ & $1,2,3,4,5,6$ & 4,6 & 4,6 & IV \\
\hline
\end{tabular}


Metodolojinin altıncı, yorumlayıcı yapısal modellemenin ise son adımında belirlenen seviyelere göre müşteri odaklı et tedarik zincirinin başarı kriterlerinden oluşan yorumlayıcı yapisal model oluşturulmuştur.

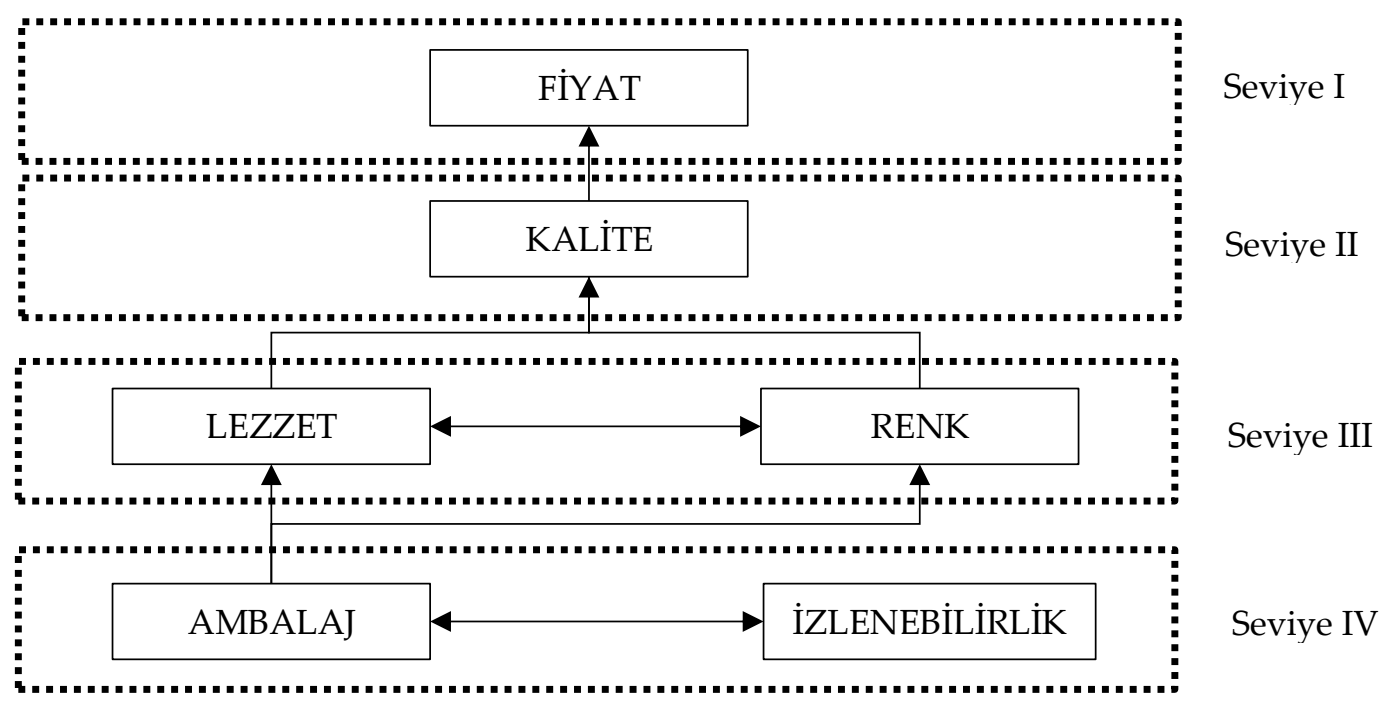

Şekil 2. Müşteri Odaklı Et Tedarik Zincirinde Başarı Kriterlerinin Yorumlayıcı Yapısal Modeli

Araştırmanın son adımında MICMAC analizi yapılmıştır. MICMAC analizinde kullanılan diyagramın 4 bölgesi vardır. Bunlar; (I) otonom kriterler, (II) bağımlı kriterler, (III) bağlantı kriterleri, ve (IV) bağımsız kriterlerdir. Öncelikle nihai erişim matrisinden (Tablo 3) yararlanılarak her bir kriterin bağımlılık ve etkileme seviyeleri belirlenmiştir (Tablo 5).

Tablo 5. Müşteri Odaklı Et Tedarik Zinciri Başarı Kriterlerinin Etkileme ve Bağımlılık Seviyeleri

\begin{tabular}{lllllll}
\hline & 1 Kalite & 2 Lezzet & 3 Renk & 4 Ambalaj & 5 Fiyat & 6 İzlenebilirlik \\
\hline $\begin{array}{l}\text { Etkileme } \\
\text { seviyesi } \\
\begin{array}{l}\text { Bağımlılık } \\
\text { seviyesi }\end{array}\end{array}$ & 2 & 4 & 4 & 6 & 1 & 6 \\
\hline
\end{tabular}

Etkileme ve bağımlılık seviyeleri belirlenmiş her bir kriter MICMAC etkileme ve bağımlılık seviyesi diyagramına konumlandırılmıştır (Şekil 3). 


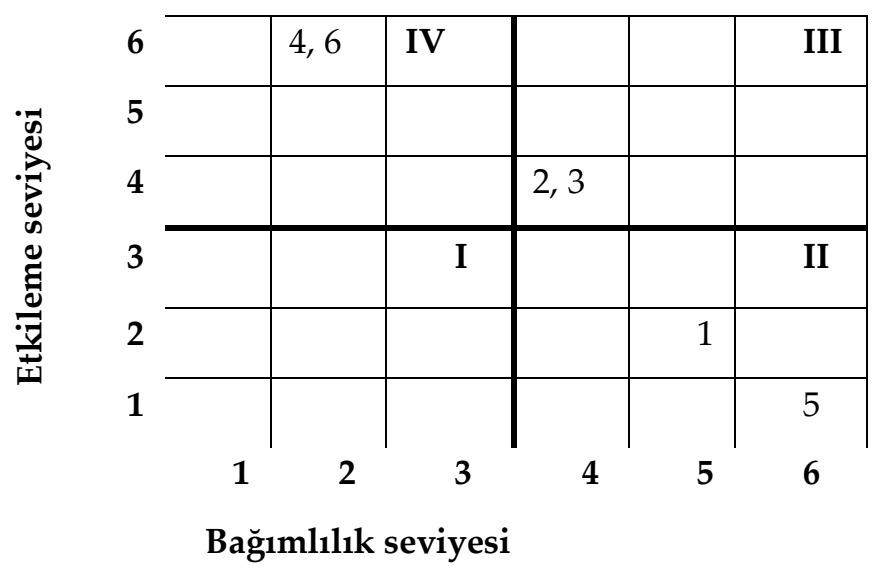

Şekil 3. MICMAC Diyagramı

\section{Bulgular}

ISM analizini sonrasında elde edilen hiyerarşik yapının (Şekil 2) en alt seviyesinde ambalaj ve izlenebilirlik kriterlerinin olduğu tespit edilmiştir. Bu iki kriter arasında aynı zamanda karşılıklı ilişki bulunmuştur. Etin rengi ve lezzeti arasında karşılıklı ilişki vardır ve her ikisi de ambalaj kriterinden etkilenmekte ve yine her ikisi de etin kalitesini etkilemektedir. Son olarak tüm faktörlerin etkilemesiyle ortaya çıan etin kalite seviyesi nihai olarak fiyatı belirlemektedir.

Tüketicilerin et satın almasında etkili olan tedarik zinciriyle alakalı faktörlerin sınıflandırılmasına ilişkin MICMAC analizi sonunda elde dilen genel bulgular ise aşağıda listelenmiştir:

a. Etin paketi ve izlenebilirliği diğer faktörleri en yüksek etkileme gücüne ve diğer faktörlerden en az etkilenme seviyesine sahip faktörlerdir.

b. Fiyat faktörü, diğer satın alma davranışını etkileyen faktörleri en düşük etkileme gücüne sahipken; diğer faktörlere en bağımlı faktör olarak bulunmuştur.

c. Analiz sonucuna göre hiçbir faktör otonom olarak tanımlanmamıştır.

d. Tat ve renk faktörleri bağlantılı faktörler olarak karşımıza çıkmaktadır.

\section{Sonuç}

$\mathrm{Bu}$ çalışmada et tedarik zinciri yönetiminde müşteri odaklı olabilmek adına belirlenen kriterlerin hiyerarşik yapısı oluşturulmuştur. Bu yapı sayesinde gerçekleştirilen her bir kriterin diğer hangi kriterlerin gerçekleştirilmesine katkıda bulunacağı ortaya konulmuştur. Hiyerarşinin en alt seviyesinde iki kriterin ön plana çıtığı görülmüştür: Ambalajlama ve izlenebilirlik. Müşteri odaklı et tedarik zinciri yönetiminde etkili olan lezzet ve renk kriterleri ise hiyerarşinin üçüncü seviyesinde bulunmaktadır, etin ambalajından ve birbirlerinden etkilenmektedir. Kalite kriteri ise yorumlayıcı yapısal modelin ikinci seviyesinde bulunmaktadır. Fiyat kriteri diğer kriterlerden etkilenip, diğer kriterleri etkileme gücüne sahip olmayan kriter olarak hiyerarşinin en tepesinde konumlanmıştır. Bu çalışmada oluşturulan hiyerarşik yapı et tedarik zinciri operasyon süreçlerinde yönetici kararlarında bir girdi teşkil edebilme kapasitesine sahiptir. Hiyerarşisinin en alt seviyesinde bulunan ambalajlama ve 
izlenebilirlik kriterleri itici kriterler olup, öncelikle onlara odaklanıldığ 1 takdirde tedarik zinciri yönetiminde önemli olan ve hiyerarşinin üst seviyelerinde yer alan diğer kriterlerin de gerçekleşmesine katkıda bulunacaktır.

MICMAC analizi sonucunda elde edilen bulgular ise ISM analiziyle benzerlik göstermektedir. Analiz sonucuna göre etin paketi ve izlenebilirliği diğer faktörleri en yüksek etkileme gücüne ve diğer faktörlerden en az etkilenme seviyesine sahip faktörlerdir. Bu faktörlerin diğer faktörleri kuvvetli şekilde etkileme kapasitesi olduğundan öncelikle odaklanılması ve önem verilmesi gereken konulardır. Fiyat faktörü, diğer satın alma davranışını etkileyen faktörleri en düşük etkileme gücüne sahipken; diğer faktörlere en bağımlı faktör olarak bulunmuştur. $\mathrm{Bu}$ sonuç diğer faktörlerde meydana gelebilecek maliyet artışının/düşüşünün fiyatı da artıracağı/azaltacağı şeklinde yorumlanabilir. Analiz sonucuna göre hiçbir faktör otonom olarak tanımlanmamıştır. Bu durum her bir faktörün tüketicilerin et satın alma davranışına az veya çok etkisinin bulunduğunu göstermektedir. Tat ve renk faktörleri bağlantılı faktörler olarak karşımıza çıkmaktadır. Bu gözlem, bu iki faktöre yönlendirilen herhangi bir eylemin diğer faktörleri etkileyebileceği gibi, kendileri üzerinde bir geri bildirim etkisinin olabileceğini göstermektedir.

\section{Tartışma ve Öneriler}

Son yıllarda gida tedarik zinciri kapsamında soğuk zincir yönetimi olağanüstü gelişme kaydetmiştir ve bu gelişimde ambalajların rolü oldukça büyüktür. Ambalaj türü aynı zamanda etin korunma türünü göstermektedir. Örneğin sıcak, soğutulmuş veya dondurulmuş olarak mı satışa çıkarıldığı kullanılan ambalajın cinsini ve aynı zamanda satışa sunulacak konumu (yerel pazar veya ihracat gibi) değiştirmektedir. Kullanılan ambalajlar, film ambalaj, paket içerisindeki havanın tamamen uzaklaştırıldığı vakum ambalaj ve paketin içindeki oksijenin uzaklaştırıldığı ve farklı ölçülerde $\mathrm{CO}_{2}$ ve $\mathrm{N}_{2}$ ile doldurulduğu modifiye atmosfer paketlemedir (Skandamis ve Nychas, 2002). Ambalajın ürünü koruma, kolaylık sağlama, tutundurma, bilgi verme, ürün imajını etkileme ve fiyatlandırma kolaylığı sağlama fonksiyonları vardır. Paketleme, et ürünlerinin raf ömrünü uzatmaya, kalitesinin sabit kalmasına ve etin güvenliğinin sağlanmasına katkıda bulunmaktadır (Liu vd., 2014). Tek bir paydaş tarafından yapılan paketlemeye, tüm tedarik zinciri boyunca, tüm paydaşlar tarafından özen gösterilmesi gerekmektedir. Depolama aşamasında veya mağazada yanlış elleçleme sonunda bozulacak olan paket hem etin bozulmasına hem de satılamamasına neden olacaktır. Dolayısıyla et tedarik zincirinde güçlü bir dikey entegrasyon ve koordinasyon ihtiyacı vardır diyebiliriz. Bu güçlü dikey entegrasyon, aynı zamanda diğer en önemli faktörlerden biri olan etin izlenebilirliğini de artıracaktır. Etin bulunduğu paket aynı zamanda pazarlama aracı olarak ta kullanılmaktadır. Diğer rakip ürünlerden farklılaşmaya, markayı ve ürün içeriğini temsil etmeye yarayan değer katıcı bir lojistik ve pazarlama fonksiyonudur.

Ambalaj ile karşıllklı ilişki içerisinde olup hiyerarşinin en temelinde bulunan diğer kriter ise izlenebilirliktir. Yapılan araştırmalarda tüketicilerin takip edebildiği, geçmişini ve hangi aşamalardan geçtiğini görebildiği etlere daha fazla ücret ödemeye razı oldukları görülmüştür (Lee vd., 2011). Çünkü izlenebilirlik etin güvenliği ve verilen bilgilerin doğruluğu hakkında doğruluğu artırmakta ve tüketicinin riskini azaltmaktadır (Merlino vd., 2018). Tedarik zinciri boyunca üyeler arasında gerçekleşen işlemlerin son tüketici tarafından görülebilmesi akıllı ambalajlar sayesinde olmaktadır. Akıllı ambalajlar sayesinde tüketici ürünün kalitesini izleme, 
kritik noktaları kontrol etme ve daha ayrıntılı bilgi edinme imkanlarına sahip olmaktadır (Dobrucka, 2013). Akıllı ambalajlar, barkod veya radyo frekans tanımlama etiketleri içeren akıllı etiketleri ve sıcaklık, süre, sızıntı, tazelik, nem gibi indikatör ve biyosensörler içeren ambalaj indikatörlerini içermektedir (Taoukis ve Tsironi, 2016).

Müşteri odaklı et tedarik zinciri yönetiminde etkili olan lezzet ve renk kriterleri ise hiyerarşinin üçüncü seviyesinde bulunmaktadır. Bir gidanın tüketilmesi sonucunda tüketici tatminini ve memnuniyetini yegâne etkileyen şey lezzettir (Killinger vd., 2004). İşleme, depolama, şoklama, dağıtım veya rafta sergilenme gibi tedarik zinciri operasyonları sırasında istenmeyen şeylerin yaşanması bu lezzeti bozacaktır. Tat duygusu ve bir yiyeceği lezzetli bulma deneyimi kişiden kişiye değişmektedir. Lezzet, tat, aroma gibi ağız içi deneyime giren duyusal tanımların yapılması oldukça zor ve karmaşıktır. Fakat yapılan araştırmalarda etin tadının kesim sonrası gerçekleştirilen tedarik zinciri faaliyetleri sırasında etkilendiği görüldüğünden, (örneğin depolama ve taşıma durumlarında etin lezzetinin değişmesi (Fonti-Furnols ve Guerrero, 2014), bu unsurda müşterilerin et seçim kriterleri arasına alınmıştır. Bu kısımda üzerinde durduğumuz tat veya lezzet unsuru ortak kabul gören iyi tat diye tabir edilebilen bazı faktörleri içermektedir. Örneğin etin yumuşaklığı. Etin yumuşaklığında hayvanın genetiğinden, tipinden ve beslenmesine kadar birçok unsur etkilidir. Fakat kesim sonrası tedarik zinciri faaliyetlerinde gerçekleşmesi muhtemel herhangi bir aksaklık bu unsurların pozitif yönde etkilerini geçersiz kılacaktır (Maltin vd., 2003). Örneğin kesim sonrası soğuk depoda bekletme ve sıcak karkasın asım işlemi etin yumuşaklığında etkili olan önemli unsurlar olarak belirtilmektedir (Font-i-Furnols ve Guerrero, 2014). Etin rengi, satış noktasında müşterinin etin tazeliğini değerlendirmede dikkate aldığı en önemli faktörlerden biri olarak ele alınmaktadır. Müşteriye göre yetersiz kırmızılıkta kahverengiye yakın bir renk, etin sağlıksız ve/veya bozulmuş olduğunun göstergesiyken, kırmızı-mor bir renk ise tazeliğinin göstergesidir (Gracia ve Magistris, 2013). O nedenle tüketicinin eti satın almadan önce ki aşamada etin rengini değerlendirmek müşterilerin karar verme sürecinde oldukça sık kullandıkları bir yöntemdir (Fonti-Furnols ve Luis Guerrero 2014). Araştırma da ambalajın etin rengini etkilediği tespit edilmiştir. Literatürde de bunu destekleyen ifadelere rastlanmaktadır. Etin doğasını ilgilendiren faktörlerden ayrı olarak ambalajlama etin rengini belirleyen en önemli faktörlerden biri olarak ele alınmıştır (Mancini, 2009). Örneğin oksijenle temas etmemiş vakumla paketlenmiş )et rengi mor iken, 15 dakika oksijene maruz kalmış miyoglobin hücreleriyle birlikte etin rengi parlak kırmızıya dönmektedir (Et ve Süt Kurumu, 2020).

Kalite kriteri ise yorumlayıc yapısal modelin ikinci seviyesinde bulunmaktadır. Etin kalitesinin değerlendirilme süreçleri tüketiciden tüketiciye değişmekle beraber bu süreçte kullanılan kriter ve ölçütleri farklılık göstermektedir. Örneğin, kimine göre etin kalitesinden anlaşılan tazeliği, az kıkırdağa sahip olması, sulu olması, hastalıklı olmaması ve iyi kokulu olmasıdır (Banović vd., 2009). Tüm bu kalite unsurları genelde et pişirildikten sonra fark edilen özelliklerdir. Pişirme işlemi gerçekleşmeden satın alma aşamasında ise etin kaliteli olup olmadığı değerlendirmesi genelde tüketiciler tarafından markaya ve etikete bakarak yapılmaktadır (Grunert vd., 2004). Kimi tüketici karbon ayak izi gibi etin çevresel etkisinin gösterildiği etiketleri ve/veya kalite belgelendirme bilgilerini içeren etiketleri etin kalite unsuru olarak değerlendirebilmektedir (Merlino vd., 2018). Troy ve Kerry (2010)'ye göre ise tüketiciler etin kalitesini satın alma aşamasında etin rengine göre değerlendirmektedir. Fonti-Furnols ve Guerrero (2014) ise etin rengine ek olarak etin yağ oranını, mermer görünümünü ve etten sızan sıvıyı tüketiciler tarafından et kalitesi değerlendirme faktörleri olarak 
belirlemiştir. Et kalitesinin değerlendirme aşamasında kullanılan ve farklı çalışmalar tarafından betimlenen tüm bu faktörlerin ortak özelliği etin dış görünüşüyle alakalıdır ve soğuk zincir tedarik zinciri operasyonlarıyla birebir bağlantılıdır. Tüketicilerden alınan bağlamsal ilişki verilerinin analizi sonucunda etin kalitesinin, etin rengi ve lezzetinden direkt olarak etkilendiği sonucuna varılmıştır. Etin rengi ve bu rengin bütünlüğü etin tazeliğinin dolayısıyla kalitesinin en önemli göstergesidir. Satıcılarda bunun farkında olup, canlı bir kırmızı bir renk ile, etin uzun raf ömrüne ve iyi bir tada sahip olduğu çıkarımını yapan tüketicilerin beklentilerini karşılamak adına çeşitli ticari yaklaşımlar kullanmaktadırlar. Örneğin perakendeciler ve yerel kasaplar gerektiğinde parlak ışıklarla etin renginin ön plana çıkmasını sağlamaktadır (Troy ve Kerry, 2010).

Fiyat kriteri diğer kriterlerden etkilenip, diğer kriterleri etkileme gücüne sahip olmayan kriter olarak hiyerarşinin en tepesinde konumlanmıştır. Fakat her ürünün değerlendirilmesinde olduğu gibi et ürününde de fiyat tüketicilerin satın alma karar aşamasında etki eden önemli bir faktör (Marian vd., 2014) olduğundan ve tedarik zinciri faaliyetlerine göre artış gösterdiğinden bu çalışmada da kriter olarak ele alınmıştır. Hatta bazı çalışmalarda güvenlik, kalite, izlenebilirlik ve menşei gibi faktörlerin önüne geçtiği görüşmüştür (örn. Du Plessis ve Gerrie, 2012). Fiyat etin türüne, kalitesine, paketlenmesine, perakendeciye ve lojistik maliyetlere göre değişkenlik göstermektedir. Bu çalışmanın sonucuna paralel olarak Merlino ve diğerleri (2018), genellikle yüksek fiyatlı bir etin müşteride kaliteli et algısı oluşturduğunu belirtmiş, Schnettler ve diğerleri (2009) ise çalışmalarında düşük dana eti fiyatıyla düşük dana eti kalitesi arasında pozitif ilişki bulmuştur.

Araştırmanın verileri et tüketicilerinden alınmıştır. Yani çalışmanın sadece müşteri ayağ gerçekleştirilmiştir. İleriki çalışmalarda, belirlenen kriterler ve oluşturulan hiyerarşik yapı, et tedarik zincirinin paydaşlarına değerlendirmeye sunulabileceği gibi kriterler arası bağlamsal ilişkiler kendilerine sorularak hiyerarşik yapı tekrar oluşturulabilir ve karşılaştırma yapılabilir. Bu paydaşlar perakendeci, mezbaha işletmecisi, çiftçi, üçüncü parti lojistik hizmet sağlayanlar veya tüm tedarik zinciri sürecini yöneten dördüncü parti lojistik hizmet sağlayanlar olabilir. Diğer yandan bu çalışma müşteri odaklı başarı kriterlerine odaklandığından aslında kesim sonrası tedarik zinciri sürecinde ki kriterleri ele almıştır. Dolayısıyla, hayvanların stres ve hijyen koşulları etin kalitesini ciddi oranda etkilediğinden (Ljungberg vd., 2007), gelecek çalışmalarda hayvanların çiftlikten araçlara yüklenmesi, mezbahalara taşınması, mezbahalarda araçlardan indirilmesi, barındırılması ve kesilmesi işlemlerini kapsayan kesim öncesi tedarik zinciri sürecindeki başarı kriterleri derlenip aralarındaki bağlamsal ilişkiler incelenebilir. Mevcut araştırmanın diğer bir kısıtı subjektif verileri kullanmasıdır. Uygulanan örneklem büyüklüğü bu çalışmada kullanılan analiz teknikleri için yeterli olsa da sonuçların genelleştirilmesi açısından uygun değildir. Dolayısıyla gelecek çalışmalarda, bu çalışmanın sonucunun geçerliliğini test etmek ve oluşturulan hiyerarşik ilişkileri doğrulamak adına Yapısal Eşitlik Modeli (YEM) yönteminin uygulanması önerilir.

\section{Bilgilendirme}

$\mathrm{Bu}$ çalışmanın 3. Ulaştırma ve Lojistik Ulusal Kongresi kapsamında Gaziantep'te sunumu gerçekleştirilmiştir. Çalışmanın sadece özet bildiri olarak sunumu yapılmış, tam metin olarak herhangi bir yerde yayını gerçekleşmemiştir. 


\section{Kaynakça}

Ahmad, M., Tang, X. W., Qiu, J. N., \& Ahmad, F. (2019). Interpretive Structural Modeling and MICMAC Analysis for Identifying and Benchmarking Significant Factors of Seismic Soil Liquefaction. Applied Sciences, 9(2), 233.

Attri, R., Dev, N., \& Sharma, V. (2013). Interpretive structural modelling (ISM) approach: an overview. Research Journal of Management Sciences, 2319, 1171.

Aung, M. M., \& Chang, Y. S. (2014). Traceability in a food supply chain: Safety and quality perspectives. Food control, 39, 172-184.

Banović, M., Grunert, K. G., Barreira, M. M., \& Fontes, M. A. (2009). Beef quality perception at the point of purchase: A study from Portugal. Food Quality and Preference, 20(4), 335-342.

Birdir, K., \& Hiçyakmazer, C. T. (2019). Otel İşletmelerinde Kırmızı Et Satın Alma ve Tedarik Sürecinin İncelenmesi. Journal of Tourism and Gastronomy Studies, 1142, 1158.

Chidambaranathan, S., Muralidharan, C., \& Deshmukh, S. G. (2009). Analyzing the interaction of critical factors of supplier development using Interpretive Structural Modeling-an empirical study. The International Journal of Advanced Manufacturing Technology, 43(11-12), 1081-1093.

Dobrucka, R. (2013). The future of active and intelligent packaging industry. Logforum, 9 (2): 103- 110. http://www.logforum.net/pdf/9_2_4_13.pdf (Erişim tarihi: 15.08.2018).

du Plessis, H. J., \& Gerrie, E. (2012). The significance of traceability in consumer decision making towards Karoo lamb. Food Research International, 47(2), 210-217.

Dubey, R., \& Ali, S. S. (2014). Identification of flexible manufacturing system dimensions and their interrelationship using total interpretive structural modelling and fuzzy MICMAC analysis. Global Journal of Flexible Systems Management, 15(2), 131-143.

Et ve Süt Kurumu (2020). Et. https://www.esk.gov.tr/tr/10998/ET Erişim tarihi: 09.03.2020

Font-i-Furnols, M., \& Guerrero, L. (2014). Consumer preference, behavior and perception about meat and meat products: An overview. Meat science, 98(3), 361-371.

Geesink, G., Robertson, J., \& Ball, A. (2015). The effect of retail packaging method on objective and consumer assessment of beef quality traits. Meat science, 104, 85-89.

Gracia, A., \& de-Magistris, T. (2013). Preferences for lamb meat: A choice experiment for Spanish consumers. Meat science, 95(2), 396-402.

Griffiths, J., James, R., \& Kempson, J. (2000). Focusing customer demand through manufacturing supply chains by the use of customer focused cells: An appraisal. International Journal of Production Economics, 65(1), 111-120.

Grunert, K. G., Bredahl, L., \& Brunsø, K. (2004). Consumer perception of meat quality and implications for product development in the meat sector-a review. Meat science, 66(2), 259-272.

Hobbs, J. E. (2016). Effective Use of Food Traceability in Meat Supply Chains. In Advances in Food Traceability Techniques and Technologies (pp. 321-335). Woodhead Publishing.

Jayant, A., Azhar, M., \& Singh, P. (2015). Interpretive structural modeling (ISM) approach: a state of the art literature review. International Journal of Research in Mechanical Engineering and Technology, 5(1), 15-21.

Jharkharia, S., \& Shankar, R. (2005). IT-enablement of supply chains: understanding the barriers. Journal of Enterprise Information Management.

Killinger, K. M., Calkins, C. R., Umberger, W. J., Feuz, D. M., \& Eskridge, K. M. (2004). Consumer sensory acceptance and value for beef steaks of similar tenderness, but differing in marbling level. Journal of Animal Science, 82(11), 3294-3301. 
Lee, J. Y., Han, D. B., Nayga Jr, R. M., \& Lim, S. S. (2011). Valuing traceability of imported beef in Korea: an experimental auction approach. Australian Journal of Agricultural and Resource Economics, 55(3), 360-373.

Liu, F., Lei, Y., Zhang, W., Sha, K., Li, H., Zhang, Z., ... \& Sun, B. (2014). Effect of different packing on quality changes of hot boning beef during storage. Journal of Agricultural Science and Technology (Beijing), 16(4), 102-108.

Ljungberg, D., Gebresenbet, G., \& Aradom, S. (2007). Logistics chain of animal transport and abattoir operations. Biosystems Engineering, 96(2), 267-277.

Maltin, C., Balcerzak, D., Tilley, R., \& Delday, M. (2003). Determinants of meat quality: tenderness. Proceedings of the Nutrition Society, 62(2), 337-347.

Mancini, R. A., \& Hunt, M. (2005). Current research in meat color. Meat science, 71(1), 100-121.

Marian, L., Chrysochou, P., Krystallis, A., \& Thøgersen, J. (2014). The role of price as a product attribute in the organic food context: An exploration based on actual purchase data. Food Quality and Preference, 37, $52-60$.

Merlino, V. M., Borra, D., Girgenti, V., Dal Vecchio, A., \& Massaglia, S. (2018). Beef meat preferences of consumers from Northwest Italy: Analysis of choice attributes. Meat science, 143, 119-128.

Miranda-De La Lama, G. C., Villarroel, M., Olleta, J. L., Alierta, S., Sañudo, C., \& Maria, G. A. (2009). Effect of the pre-slaughter logistic chain on meat quality of lambs. Meat Science, 83(4), 604-609.

Mohebalizadehgashti, F., Zolfagharinia, H., \& Amin, S. H. (2020). Designing a green meat supply chain network: A multi-objective approach. International Journal of Production Economics, 219, 312-327.

Pizzuti, T., Mirabelli, G., Grasso, G., \& Paldino, G. (2017). MESCO (MEat Supply Chain Ontology): An ontology for supporting traceability in the meat supply chain. Food Control, 72, 123-133.

Schnettler, B., Vidal, R., Silva, R., Vallejos, L., \& Sepúlveda, N. (2009). Consumer willingness to pay for beef meat in a developing country: The effect of information regarding country of origin, price and animal handling prior to slaughter. Food Quality and Preference, 20(2), 156-165.

Sharma, V. K., Chandna, P., \& Bhardwaj, A. (2017). Green supply chain management related performance indicators in agro industry: A review. Journal of Cleaner Production, 141, 1194-1208.

Singh, R. K., Garg, S. K., \& Deshmukh, S. G. (2007). Interpretive structural modelling of factors for improving competitiveness of SMEs. International Journal of Productivity and Quality Management, 2(4), 423-440.

Skandamis, P. N., \& Nychas, G. J. E. (2002). Preservation of fresh meat with active and modified atmosphere packaging conditions. International journal of food microbiology, 79(1-2), 35-45.

Taoukis, P., \& Tsironi, T. (2016). Smart packaging for monitoring and managing food and beverage shelf life. In The stability and shelf life of food (pp. 141-168). Woodhead Publishing.

Troy, D. J., \& Kerry, J. P. (2010). Consumer perception and the role of science in the meat industry. Meat science, 86(1), 214-226.

Van Wezemael, L., Caputo, V., Nayga Jr, R. M., Chryssochoidis, G., \& Verbeke, W. (2014). European consumer preferences for beef with nutrition and health claims: A multi-country investigation using discrete choice experiments. Food Policy, 44, 167-176.

Wen-li, L., Humphreys, P., Chan, L. Y., \& Kumaraswamy, M. (2003). Predicting purchasing performance: the role of supplier development programs. Journal of materials processing technology, 138(1-3), 243-249.

Yamoah, F. A., \& Yawson, D. E. (2014). Assessing supermarket food shopper reaction to horsemeat scandal in the UK. International Review of Management and Marketing, 4(2), 98-107. 